\title{
Investigation of Seismic Behaviour of Steel Pallet Rack Frames
}

\author{
Abba Mas'ud Alfanda ${ }^{1}$, Guven Kiymaz ${ }^{2}$ \\ ${ }^{1}$ Civil Engineering Department, Fatih University, Istanbul, Turkey \\ ${ }^{2}$ Civil Engineering Department, International University of Antalya, Antalya, Turkey
}

Email address:

meetabba22@yahoo.co.uk (A. Mas'ud Alfanda),gkiymaz@gmail.com (G. Kiymaz)

To cite this article:

Abba Mas'ud Alfanda, Guven Kiymaz. Investigation of Seismic Behaviour of Steel Pallet Rack Frames. American Journal of Engineering and Technology Management. Vol. 2, No. 2, 2017, pp. 13-19. doi: 10.11648/j.ajetm.20170202.12

Received: February 9, 2017; Accepted: March 6, 2017; Published: June 30, 2017

\begin{abstract}
One of the most significant uses of cold-formed members is for steel storage racking structures, such as pallet, drive in, and drive through racking systems. In the current competitive industry, pallets and storage racks may support heavy loads that have the potential to injure workers and damage equipment if the pallets and racks fail and loads fall. Hence, storage racks must remain structurally sound. Additionally, when subjected to earthquake loading, they can exhibit very large transverse displacement. In spite of their complexity, racks are able to carry heavy loads, though they are designed as lightly as possible, and industries often rely on 3-dimensional Finite Element Analysis to achieve this objective. This study, presents a Finite Element model of a conventional rack structure modeled using the commercial software SAP2000. In order to investigate the seismic behaviour of rack frames under real earthquake ground motions, the Time History Analysis was performed with rigid, semi-rigid and pinned connections. The study provided a strong case for the possible benefits of semirigid steel frames and motivated the need for detailed, accurate, and reliable analytical models of the connection. Neglecting semi-rigidity cause stiffening of frames resulting in shorter fundamental period and larger lateral displacement which in turn results in a significant error in the evaluation of dynamic loads.
\end{abstract}

Keywords: Dynamic Time History Analysis, Pallet Racks, Cold Formed Steel, Earthquake, SAP2000

\section{Introduction}

One of the most significant uses of cold-formed members is for steel storage racking structures, such as pallet, drive in, and drive through racking systems [3]. Storage racks are usually found in industry used for storing goods, mostly on pallets and made from cold-formed steel profiles. In particular, steel storage racking systems are building structures that are well known by the fact that they carry live loads much larger than self- weight and rise to considerable height. Storage racking systems are as well differentiated by the great variety of typologies, shapes and sizes, ranging from large warehouses to small shelves for offices or shops. This imposes different importance from a design point of view, and a somewhat incompatible situation regarding which design codes to use and when to use them. Their behavior is also influenced by the geometry of their structural components (high slenderness elements, open section profiles hence prone to buckling problems) as well as by the nonlinear behavior of their joints (beam-to-upright and baseplate). Thus, many difficulties arise in the prediction of their structural behavior or modeling problems of beam-to-upright and base-plate connections [23].

The research motivation for this study originates from the need to get a deeper understanding of the influence of seismic action on the structural behavior of thin-walled frames. As the special geometry of these thin-walled structures of high slenderness and their non-linear behavior require specific regulations for a successful and accurate modeling. This thesis aims at developing an accurate and efficient material geometric non-linear time history analysis for pallet rack structural behavior by the use of the SAP2000 (version 12).

Aim and Objectives 
The main aim of the study is to investigate the range of response characteristics of pallet rack frames, having different connection types subjected to seismic loading. More precisely, the study deals with down-aisle frames and follows three definite objectives:

1. To obtain dynamic characteristics which are fundamental periods, mode shapes response to various strong ground motions of conventional pallet racking systems, made up of cold form sections.

2. To determine the maximum base shear at the time of collapse and maximum displacement for different connection types.

3. To investigate the effect of beam-column connections on structural behavior of rack system for various connection types under horizontal and vertical loads.

\section{Methodology}

The most accurate method of seismic demand prediction and performance evaluation of structures is nonlinear time history analysis. However, this technique requires the selection and employment of an appropriate set of ground motions and having a computational tool able to handle the analysis of the data and to produce ready-to-use results within the time constrains of design offices [2]. In this research, modeling of conventional pallet racking systems was carried out using the finite element program. Nonlinear time history analysis found to be a useful analysis tool for the conventional pallet racking systems giving good estimates of the maximum roof displacement, base shears and time history graphs.

\subsection{Material Properties}

The material properties of the frame members are given in Table 1

Table 1. Material Properties.

\begin{tabular}{ll}
\hline Modulus of Elasticity, E & $24856 \mathrm{MPa}$ \\
Poisson's Ratio, U & 0.2 \\
Minimum Yield Strength, Fy & $228 \mathrm{MPa}$ \\
Minimum Tensile Stress, Fu & $310 \mathrm{MPa}$ \\
\hline
\end{tabular}

\subsection{Frame Section Properties}

The tables below contain section properties as obtained from the mass properties using AUTO CAD software. This data was used for input into the SAP 2000 model

Table 2. Section Properties.

\begin{tabular}{llll}
\hline Properties & $\begin{array}{l}\text { Upright } \\
\text { Section }\end{array}$ & $\begin{array}{l}\text { Beam } \\
\text { Section }\end{array}$ & $\begin{array}{l}\text { Bracing } \\
\text { Section }\end{array}$ \\
\hline $\begin{array}{l}\text { Area }\left(\mathrm{mm}^{2}\right) \\
\text { Moments of inertia about X-axis }\end{array}$ & 922 & 561 & 302 \\
$\left(\mathrm{~mm}^{4}\right)$ & 672688 & 1362201 & 1362201 \\
Moments of inertia aboutY-axis $\left(\mathrm{mm}^{4}\right)$ & 1854787 & 273021 & 273021 \\
Radii of gyration about X-axis $(\mathrm{mm})$ & 27 & 49 & 49 \\
Radii of gyration about Y-axis $(\mathrm{mm})$ & 45 & 22 & 22 \\
Section Modulus about X $\left(\mathrm{mm}^{3}\right)$ & 672688 & 10920 & 150 \\
Section Modulus about X $\left(\mathrm{mm}^{3}\right)$ & 30913 & 24464 & 19460 \\
Torsional Constant & 5586 & 723874 & 723874 \\
\hline
\end{tabular}

\subsection{Elements and Profiles}

The selection of cross-section size and lengths employed was designed to ensure that the specimen member slenderness covered most practical range. The uprights as well as the pallet beams of the structures were simulated as beam elements whereas all the bracings were simulated as truss elements. In Sap2000 all the above elements are referred to as Frame Sections. The profiles of the elements were defined in SAP's General Section where the geometry and the materials can be specified. The $3 \mathrm{D}$ frames refer to modeling the entire pallet rack frame and open-section beam elements are used to model and braces.

The dimensions of the beam and column used in this study are shown in Figures 1 and 2

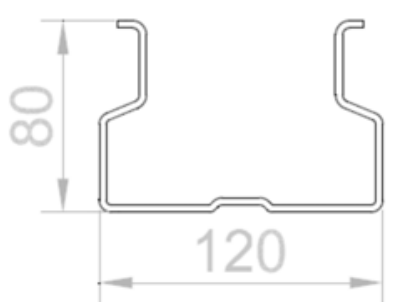

Figure 1. Upright Section and Dimensions.

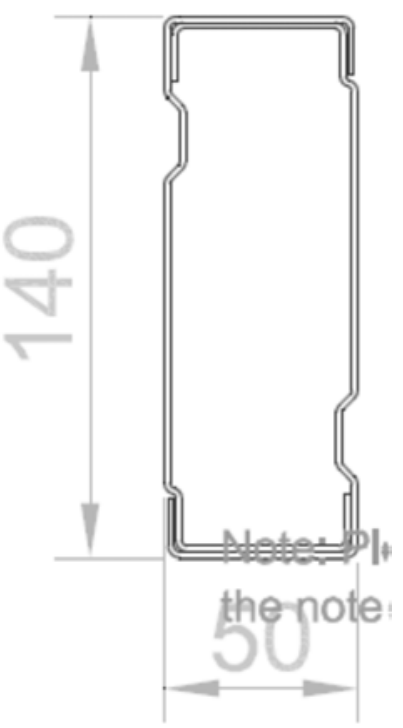

Figure 2. Beam Section and Dimension.

\subsection{Geometry and Model Configuration}

All the configurations examined were according to a X-Y$\mathrm{Z}$ grid defining five bays, a front and a rear vertical level and four floors. The grid was divided in a primary grid and a secondary grid. Global axes are axis $\mathrm{X}$ is parallel to picking bays (down-aisle direction), axis $\mathrm{Y}$ is parallel to upright frames (cross-aisle direction), and axis $\mathrm{Z}$ is the vertical direction all the secondary nodes in general. The 4-story, 5bay frame is $5.6 \mathrm{~m}$ high and $15 \mathrm{~m}$ wide was selected from the frames studied to represent a typical rack used for merchandise storage. 


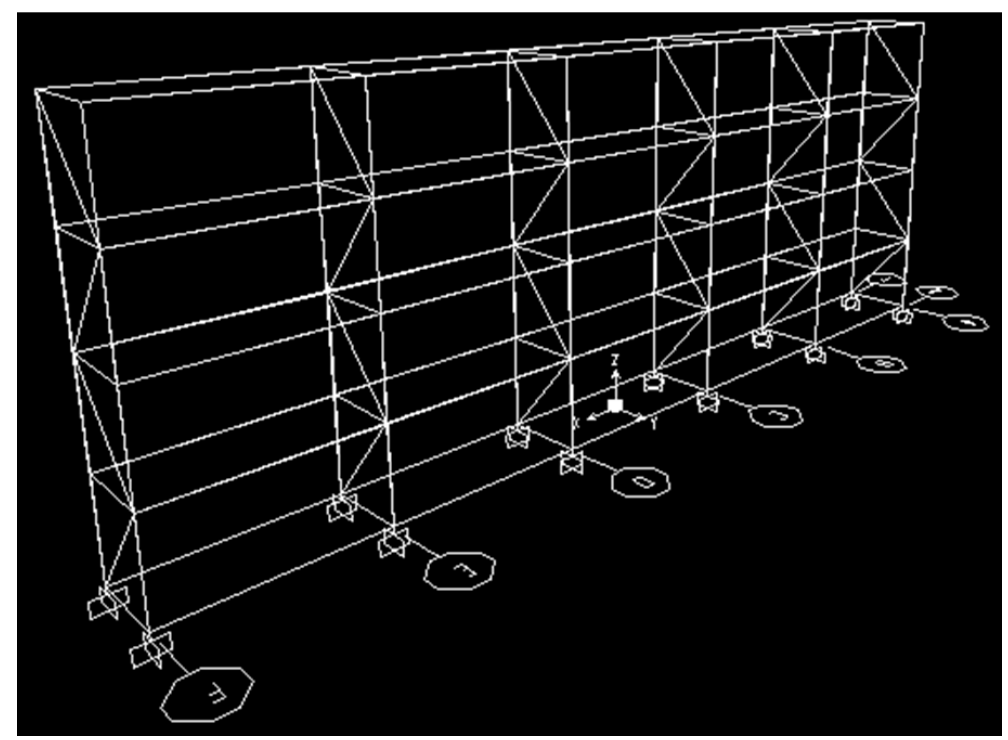

Figure 3. 3D View of the Model Configuration.

\subsection{Loading Pattern}

The applied loads are vertical and horizontal. The vertical loads consist of the dead load of the structure as well as the pallets. Pallet loads were applied in the form of distributed loads of equal magnitude $(5 \mathrm{kN} / \mathrm{m})$ on each of the bays' frame. To get the pallet effective weight, the 0.67 coefficient for the pallet weight comes not from the average load but from an evaluation of the amount of load that participates in developing the dynamic seismic force. FEM 10.2.08 stated that experience has shown that the whole mass of the merchandise stored on the storage rack system does not participate entirely to the inertia generated from the ground motion. There is some friction inducing energy dissipation for the relative movement between the storage racks. To get the pallet effective weight, the 0.67 coefficient for the pallet weight comes not from the average load but from an evaluation of the amount of load that participates in developing the dynamic seismic forces

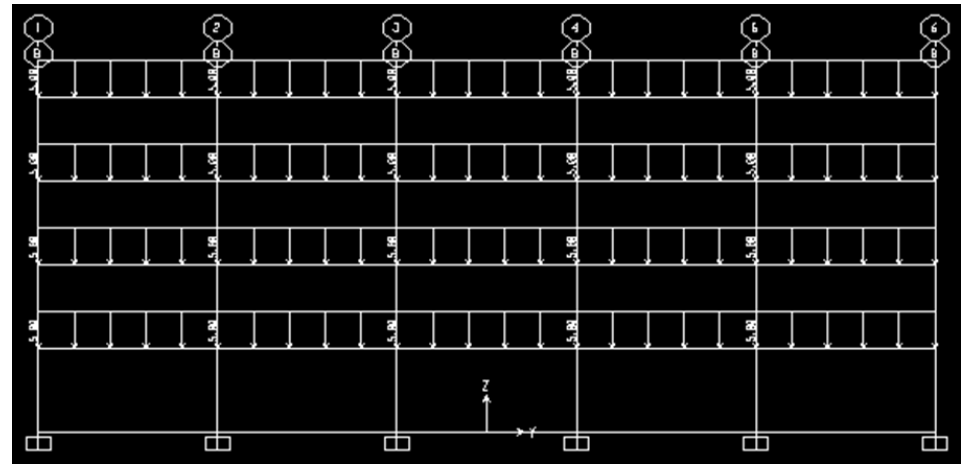

(a) Case 1 Loading Condition

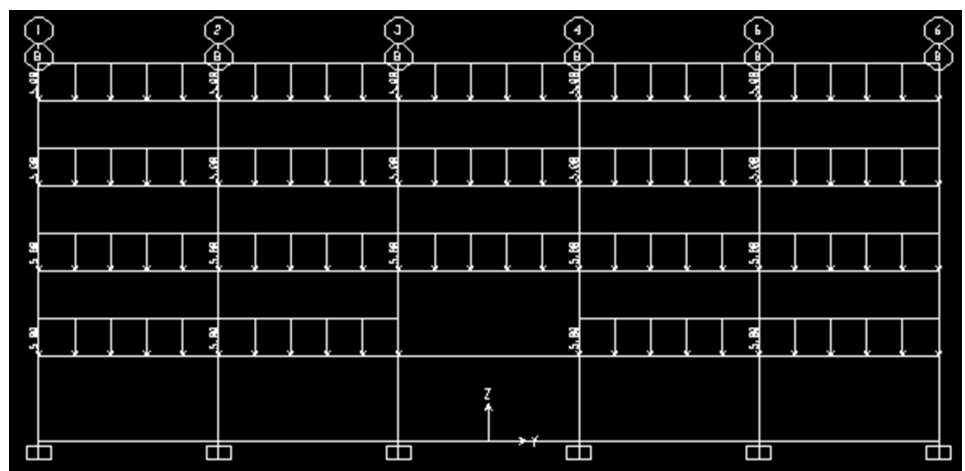

(b) Case 2 Loading Condition

Figure 4. Loading Pattern. 


\subsection{Beams-to-Column Connection Beam End Connectors}

The behavior of the beam end connector is crucial for the stability of the whole structure since it provides the frame action (moment resistance) longitudinally. These are hooked, and their calculations are only experimental in order to specify the rotational stiffness of the connection and its strength. Moment-rotation curve were used to simulate, they were input in the models using partial fixity releases [17]. Taking account two extreme conditions, namely rigid and pinned have been considered for beam-to-column connections. For the joint at each end of the beam, three different forms of behaviour were considered:

\subsubsection{Pinned Connection}

Pinned connections, no end moment is developed and the bending moment diagram can be determined by statics, with a maximum moment as shown in the Figure 5

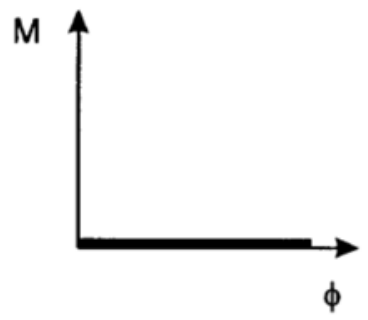

a) pinned

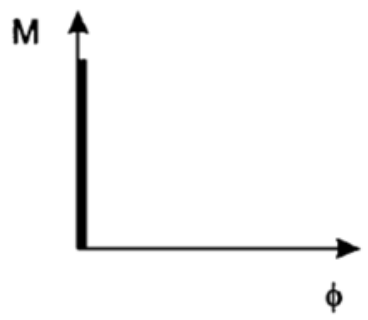

b) rigid

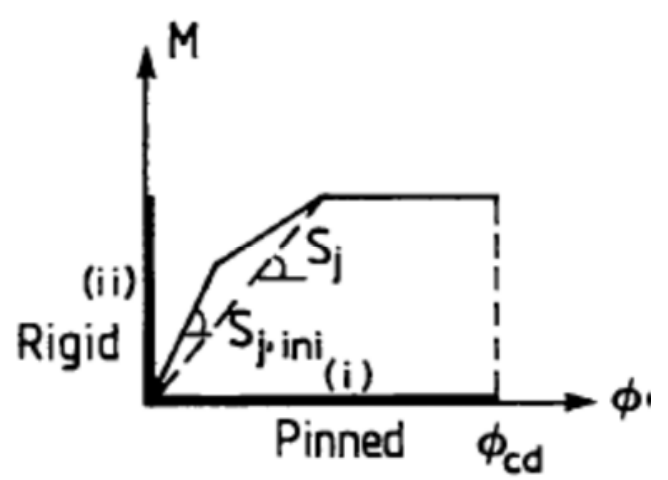

Figure 5. Major Connection Characteristics [12].

\subsubsection{Rigid Connection}

In rigid connections, no rotation occurs at the ends of the beam. In conventional design of continuous structures, the connections are proportioned to resist whatever end moments result from the global analysis of the structure, and the connections resistance provided is therefore as great as that of the connected beam.

\subsubsection{Semi-Rigid Connection}

A well-known method of allowing for semi-rigid connections action in global analysis is to modify the beam stiffness to an effective value. For similar reasons, the acceptable boundaries for the rigid and pinned idealisations are expressed in terms of beam stiffness related to initial joint stiffness. Determined in terms of acceptable errors resulting from the assumption of fully-rigid or truly pinned behaviour. Therefore the beam-column connections were semi-rigid and the experimental moment-rotation curves were incorporated into the connection behaviour [1]

\subsection{Experimental Test Programme}

Since the moment-rotation response at the beam-to-column connection is non-linear and affected by the looseness of the connections. To achieve an accurate semi-rigid joint, the inelastic beam to column connection means considering the connection to be semi-rigid, setting the moment and rotation relationship as elastic plastic. In this study, bending test was used to determine the moment-rotation behaviour of the semi-rigid connection of racks and it was found to be stiffness $\mathrm{K}_{\Theta}=153.68 \mathrm{kN}-\mathrm{m} /$ radian.

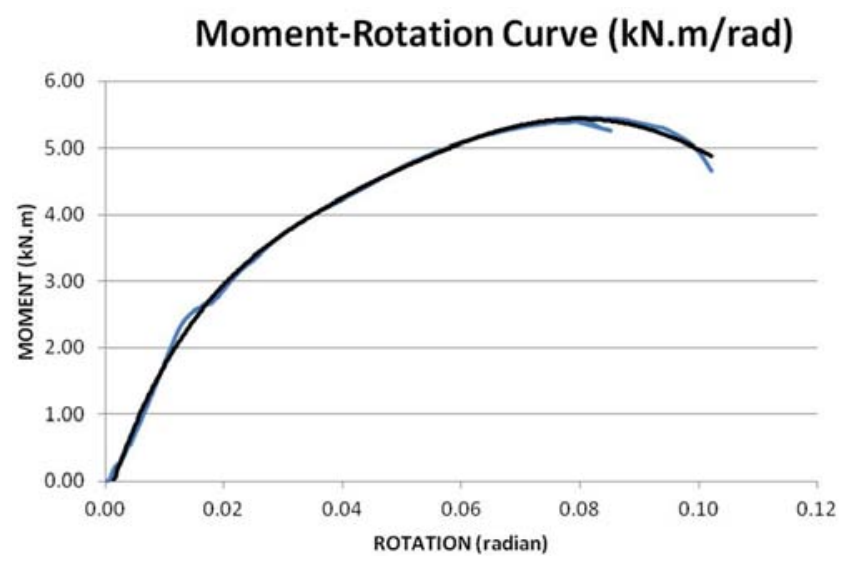

Figure 6. Experimental Moment-Rotation Curve for Beam End Connection.

\section{Earthquake Ground Motions}

The nonlinear Time history analysis of the frames was subjected to three different ground motions obtained from the Pacific Earthquake Engineering Research Center (PEER) Ground Motion Database. These are Sakarya (Turkey), Loma Prieta (California), and Kobe (Japan) Earthquake ground motions. The rack models were analyzed both in down and cross aisle directions. Model of conventional pallet racking systems was carried out using the SAP2000 finite element program. Three connection cases were considered for each of the ground motions.

\subsection{Modeling Assumptions}

In order to study the dynamic behaviour for the down aisle of pallet racks, the following assumptions similar to [2] were made:

1. Uniform beam to upright connection is used throughout the frame.

2. The beams are spaced uniformly along the height of frame

3. All connections of the racks experience simultaneously similar rotations at all times. This assumption implies that the connection rotational stiffness is smaller than the rotational stiffness of the beams and uprights. 
4. For this study the column base connection is assumed to be fixed in all six degrees of freedom, as base plates are fixed with two or more bolts normally [2].

\section{Result and Discussion}

A summary of the main results obtained from the numerical analysis is presented with the aim of allowing understanding of the actual dynamic behavior of steel pallet racks under seismic conditions. The results obtained from time-history analysis are compared with respect to the fundamental period, the maximum displacement, maximum and base shear under seismic loads in the preceding tables and charts. For comparison, the pinned and rigid-connection cases are also included in the studies.

\subsection{Period of Vibration}

The variation of the first three periods of vibration of rack fames with various connection types is given in Table 3 Clearly, the stiffness of the connections affect the periods of the frames significantly. It is interesting to see that the relationship between the periods of vibration of the rack frames is almost linear.

Table 3. Comparison of Fundamental Period Results.

\begin{tabular}{lllllll}
\hline \multirow{2}{*}{ Mode } & \multicolumn{2}{l}{ Rigid Connection } & & \multicolumn{2}{l}{ Semi-Rigid Connection } & \multicolumn{2}{c}{ Pinned Connection } \\
\cline { 2 - 6 } & CASE I & CASE II & CASE I & CASE II & CASE I \\
\hline 1 & 2.797466 & 2.796493 & 3.35102 & 3.350081 & 6.86404 \\
2 & 1.14217 & 1.141685 & 1.171322 & 1.170888 & 1.250283 & 1.863118 \\
3 & 0.81508 & 0.812973 & 0.903422 & 0.90115 & 1.249506 & 115341 \\
\hline
\end{tabular}

\section{Fundamental Period (s)}

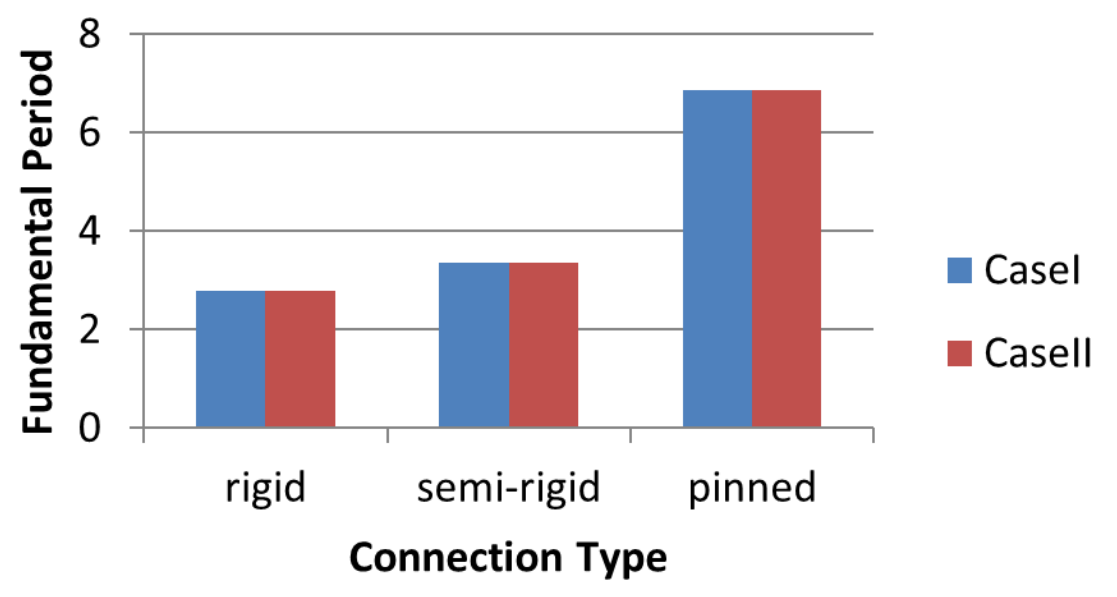

Figure 7. Comparison of Fundamental Period Result.

The natural periods of the first three modes of all the three connection cases are compared in Figure 7. From this figure, it is seen that the natural periods of the frames were almost the for a particular connection type regardless of the loading cases. Comparing the values of the period for semi-rigid frames with those of rigid and pinned frames, the first mode period is about 1 second higher than the two connections. It can be seen that fundamental period for a semi-rigid frame is longer than that of rigid but lower than pinned connections. This may be due to the effect of structural stiffness altering the time periods. Longer period produces lower frequency which means reduction the effect of seismic forces. However, the movement of the rack system should be enough to achieve increasing period to a desired level, while at the same time not exceeding an acceleration threshold over which product will fall off the shelves.

\subsection{Modal Displacement and Maximum Displacement Under Earthquake}

Maximum Modal

Displacement(mm)

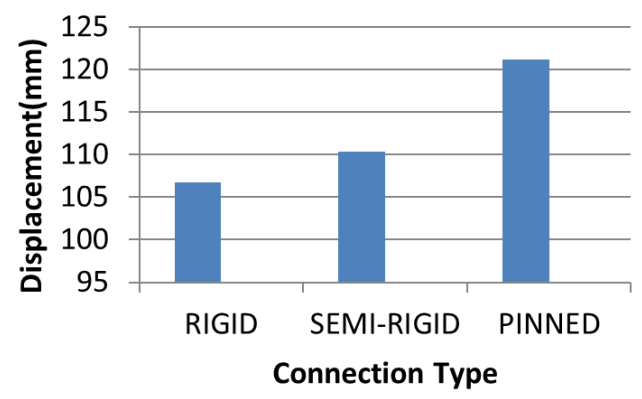

Figure 8. Variations in Modal Displacement. 
Figure 8 depicts the variation of maximum modal displacement response of the top level obtained for the numerical model with different connections based on stiffness. As expected the larger the flexibility of the connection, the larger the top maximum displacement. It clearly shows that, under the above semi-rigid, constitutes an optimum of $111 \mathrm{~mm}$ which is $5 \%$ higher than rigid frame. For pinned frames, displacements are slightly overestimated (about $8 \%$ ) higher than the semi-rigid case.

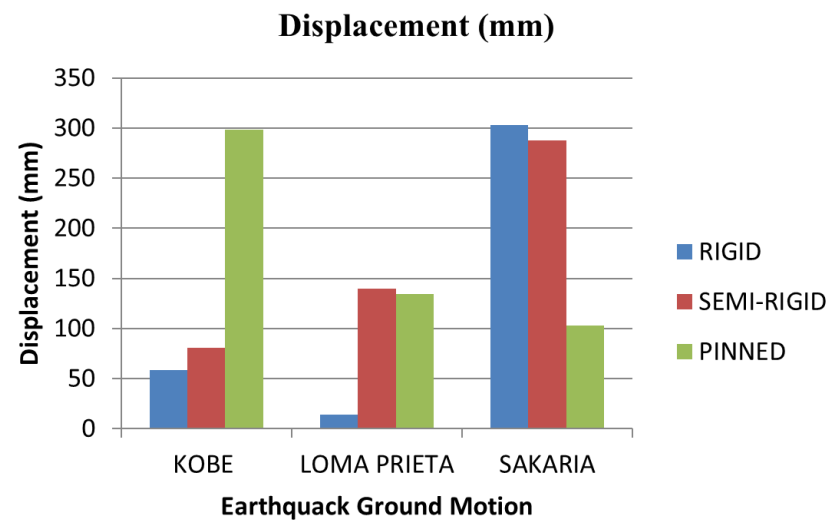

Figure 9. Comparison of Displacement under Earthquake.

It is also notable from the Figure 9 that the time-history record employed in the seismic analysis influences the maximum displacement due to the differences found in the Kobe, Loma Prieta and Sakarya. The three chosen ground motions featured significantly different maximum displacement as observed in their respective responses. The displacement of semi-rigid connection is larger than that of rigid frames with the exception of Sakarya Earthquake. This could be possibly due to the inherent modeling assumptions made in the course numerical design.

\subsection{Maximum Base Shear}

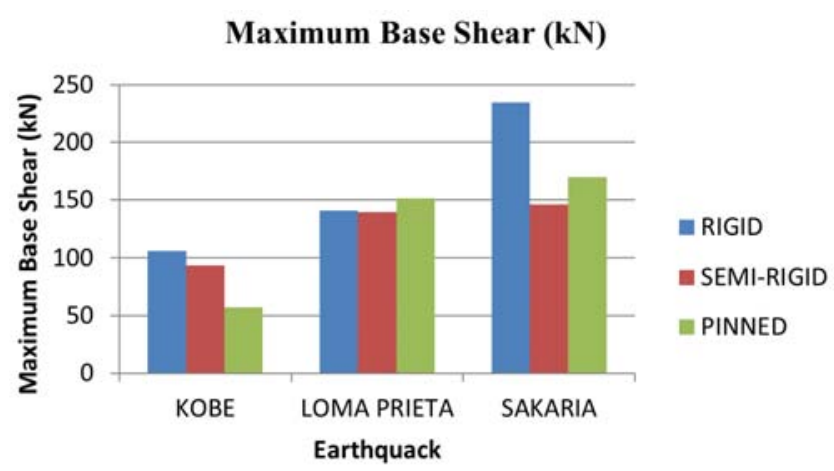

Figure 10. Bar Chart Showing Variations in Seismic Base Shear.

Figure 10 shows the variation of the base shear of the frame at the base. It is seen that rigid connection can result in the large base shear force response for all the three earthquakes considered in this study. For semi-rigid connection, the maximum base reaction becomes the smallest. For instance, the base shear for Sakarya earthquake with perfectly rigid connection is $235 \mathrm{kN}$, with pinned connection is $169 \mathrm{kN}$, leaving $28 \%$ reduction of the base shear response. With semi-rigid connection the base shear further reduced to $145 \mathrm{kN}$. Thus, the overall earthquake resistance of the pallet rack under study could be significantly enhanced through the use of semi-rigid connections.

\subsection{Maximum Interstory Drift Ratio}

Interstory drift is a measure of how much one floor or roof level displaces under load relative to the floor level immediately below. It is generally expressed as a ratio of the difference in deflection between two adjacent floors divided by the height of the story that separates the floors.

Table 4. Maximum Interstorey Drift.

\begin{tabular}{llll}
\hline Connections & Rigid & Semi-rigid & Pinned \\
\hline Maximum Drift Ratio & 0.01557 & 0.02071 & 0.0431 \\
\hline
\end{tabular}

According to the NEHRP Recommended Seismic Provisions sets maximum permissible interstory drift limits based on a structure's Occupancy Category and construction type $\Delta \mathrm{a}$, varies from 0.007 to 0.025 depending on the structure's Occupancy Category and construction types. Hence the intertorey drift for rigid and semi-rigid are within the acceptable limit

\section{Overall Dicussion}

1. There is no apparent difference between Case 1 and Case 2 in terms of period of vibration for all the three connection types considered. These results provide confirmatory evidence that load case 2 cannot be considered as the critical loading contrary to the FEM 10.2.02: (The Design of Static Steel Pallet Racking) as such static and dynamics design cannot be treated in the same way..

2. Base shear as the maximum expected lateral force that will occur due to the seismic ground motion found be dependent on the probability of the ground motion, the frame joint connections associated with rack structural configuration and the natural period of vibration.

3. The result indicates good behavior of the semi-rigid frame under seismic loads; it reveals that the structure utilizes its capacity lying in the inelastic zone. Therefore semi-rigid connection is more effective than the usual, and that they can deform in a ductile manner, dissipating more seismic energy. Their advantages, in terms of lower construction costs and simple fabrication, are therefore not till now utilized in seismic design. Conversely, dependence on the rigidity of fully-welded connections under earthquake loading has recently come under question, particularly in Japan, as a consequence of difficulties associated with quality control of welding processes [12].

\section{Conclusion}

The study concluded that semi-rigid connections did account for precise stiffness of the rack frames, also adding a 
considerable dissipation of seismic energy and generally providing significant reductions in the base shear a structure experiences. The real response of the semi-rigid frame was found to be intimately dependent upon the dynamic properties of the frame and the characteristics of the ground motion, requiring detailed analysis for each semi-rigid frame prior to the construction of the frames. In the interests of economy the designer need to choose a form of connection whose stiffness does not approximate to either rigid or pinned behaviour. In this way arrangements, classification by rotational stiffness therefore to model the structural frame in a realistic manner whilst providing freedom to choose the connection stiffness most suited to the particular rack connection.

\section{References}

[1] Abdel-Jaber, M. R., Beale, G., and Godley, M. H. R., “A Theoretical and Experimental Investigation of Pallet Rack Structures Under Sway," Journal of Constructional Steel Research, Vol. 62, No. 1-2, pp. 68-80, 2006.

[2] Bajoria, K. M., and Talikoti, R. S., "Determination of Flexibility of Beam-to-Column Connectors Used in Thin Walled Cold-Formed Steel Pallet Racking Systems," ThinWalled Structures, Vol. 44, No. 3, pp. 372-380, 2006.

[3] Bajoria, K. M., Sangle, K. K., and Talicotti, R. S., "Modal Analysis of Cold-formed Pallet Rack Structures with Semirigid Connections," Journal of Constructional Steel Research, Vol. 6, pp 428-441, 2010.

[4] Baldassino N. and Zandonini R., "Numerical and Experimental Analysis of Base-plate Connections of Steel Storage Pallet Racks," Proceeding of XVIII Conference C. T. A., pp. 127-136, Venezia, 2001.

[5] Bernuzzi, C., and Castiglioni, C. A., "Experimental analysis on the cyclic behaviour of beam-to-column joints in steel storage pallet racks," Thin-Walled Structures, Vol. 39, No. 10, pp. 841-859, 2001.

[6] British Standards Institution, Eurocode 8: Design of structures for earthquake resistance-Part 1: General rules, seismic actions and rules for buildings, London, UK, BS EN, 1998-1, 2004.

[7] Castiglioni C. A., Seismic Behaviour of Steel Storage Pallet Racking Systems, Structural Engineering Department of Politecnico di Milano, Milano, 2008.

[8] Castiglioni, C. A., and Kanyilmaz, A., "Seismic Behavior of Steel Storage Pallet Racking Systems," 5th National Symposium on Steel Structure on Steel, Istanbul, Turkey, 2013.

[9] Charlotte, NC., 2002 edition RMI, Commentary to Specification for the design testing and utilization of industrial steel storage racks, Rack Manufacturers Institute, 2007.
[10] Computers and Structures Inc., CSI Analysis Reference Manual for SAP2000, ETABS, and SAFE, Berkeley, California, USA, 2010

[11] Degée, H., and Denoël, V., "Numerical Modelling of Storage Racks Subjected to Earthquake", ECCOMAS Thematic Conference on Computational Methods in Structural Dynamics and Earthquake Engineering, 13-16 June 2007, Rethymno, Crete, Greece, 2007.

[12] Elnashai, A. S. and Elghazouli, A. Y., "Economy Studies of Steel Building Frames with Semi-Rigid Joints," Journal of Constructional Steel Research, Vol. 29, pp. 149-174, 1994.

[13] Faella, C., Piluso, V., and Rizzano, G., Structural Steel Semirigid Connections: Theory, Design and Software, CRC Press, New York, NY, USA, 2000.

[14] FEM 10.2.08, The Seismic Design of Static Steel Pallet Racks, Federation Europeen de la Manutention, final draft, December 2005.

[15] FEMA, The 2009 NEHRP Recommended Provisions for New Buildings and Other Structures Provisions (FEMA 750), Prepared for FEMA by the Building Seismic Safety Council (National Institute of Building Sciences), Washington, DC, 2009.

[16] Higgins, P., and Malibu, CA., "Uniform Building Code," International Conference of Building Officials, Whittier, CA, 2004.

[17] Kartal, M. E., Basaga, H. B., Bayraktar, A., and Muvafik, M., "Effect of semi-rigid connection on structural Responses," Electronic Journal of Structural Engineering, Vol. 10, 2009.

[18] Lim, J. B. P., and. Nethercot, D. A.,"Finite element idealization of a cold-formed steel portal frame," Journal of Structural Engineering, Vol. 130, No. 1, pp. 78-94, 2004.

[19] Rasmussen, K. J. R., and Gilbert, B. P., Analysis-Based 2D Design of Steel Storage Racks, 2010, http://www.sydney.edu.au/engineering/civil/publications/2010 /r908.pdf.

[20] RMI, Specification for the design testing and utilization of industrial steel storage racks, Rack Manufacturers Institute, 2002.

[21] Rondal, J., "Cold formed steel members and structures: general report," Journal of Constructional Steel Research, Vol. 55, No. 1-3, pp. 155-158, 2000.

[22] Sarawit, A and Peköz, T., "Design of Cold-Formed Steel Frames and Beam- Columns," Proceedings of Structural Stability Research Council Annual Conference, Baltimore, MD, 2003.

[23] Stella, A., Seismic Performance of Steel Pallet Racks, Postgraduate Diploma Thesis, National Technical University of Athens, 2012.

[24] Storage Racks in Seismic Areas (SEISRACKS), Research Programme of the Research Fund for Coal and Steel RTD, Final Report, May 2007 http//www.csiberkeley.com. 